\section{A redução da discricionariedade administrativa por meio da ampliação dos espaços de deliberação coletiva na elaboração das políticas públicas: uma análise sob o enfoque do direito social à moradia}

\section{The reduction of administrative discretion by expanding the spaces of collective deliberation in shaping public policy: an analysis from the standpoint of social housing}

Daniel Augusto Mesquita

${ }^{1}$ Procurador do Distrito Federal. Bacharel em Direito pela Universidade de Brasília - UnB. Mestrando pelo Instituto Brasiliense de Direito Público - IDP. Pós-graduado em direito público. Coautor do livro Direito Administrativo da Série Advocacia Pública da editora Método. Professor de Direito Administrativo e de Estatuto da OAB.

\section{Resumo}

O artigo pretende, a partir da análise da estrutura da administração pública constituída sob o modelo liberal, identificar o distanciamento das decisões administrativas discricionárias das demandas plurais da sociedade. A colocação do cidadão no centro dessas decisões, como efetivos autores dos próprios direitos, por meio de uma democracia participativa, em que o indivíduo atua não só no processo de determinação do orçamento público, mas nas decisões do Poder Executivo quando da fixação de critérios para a execução desse orçamento, é elemento fundamental para conferir legitimidade às decisões estatais. A análise dos critérios de preferência para a distribuição de moradias criados pelo Distrito Federal servirá como mote para demonstrar como a participação do cidadão beneficiário pode contribuir para a fixação de critérios mais adequados à demanda da sociedade.

Palavras-chave: Participação. Cidadania. Moradia. Critérios. Programas sociais.

\begin{abstract}
The article intends, from the analysis of the structure of government established under the liberal model, to identify the distance of discretionary administrative decisions from the demands of a plural society. Placing the citizen at the heart of these decisions, as effective authors of their rights, through a participatory democracy, in which the individual acts not only in the process of determining the public budget, but the decisions of the executive branch when setting criteria for the execution of the budget, it is fundamental to confer legitimacy on government decisions. The analysis of the establishments of preference criteria for the distribution of housing created by the Federal District, Brazil, will demonstrate how citizen effective participation may contribute to establishing criteria more suited to the demands of society.
\end{abstract}

Keywords: Participation. Citizenship. Housing policy. Social programs. 


\section{Introdução}

Quando tratamos de efetividade dos direitos sociais, o quadro que vem a mente é de uma necessidade ilimitada de bens e serviços por parte da sociedade e de um Estado que se depara com a dificuldade diária de alocar os recursos, sempre insuficientes, onde eles serão melhor aproveitados.

Isso decorre da própria natureza dos direitos sociais, que possui característica eminentemente positiva, pois demanda gastos dos recursos do Estado com o propósito de prover ao cidadão uma necessidade básica para a sua existência digna.

A dificuldade de decidir como alocar de forma ideal esses recursos cresce na medida em que o Estado, nesse processo decisório, se distancia daqueles que serão os beneficiários dos direitos promovidos.

O modelo de administração pública desenvolvido desde o surgimento do Estado Moderno separa a realidade do Estado da realidade do cidadão e constitui um ambiente decisório amplamente discricionário, em que o diálogo entre a sociedade e o Estado é inexistente ou, no mínimo, ineficiente. Isso proporciona um ambiente de decisão em que o gestor público deixa de se pautar pelas necessidades da comunidade e se guia pelas influências político-partidárias ou, o que é comumente observado, por interesses escusos e ilegítimos.

A constituição das decisões administrativas a partir do diálogo com a sociedade é medida que, muito além de conferir direitos sociais mais adequados aos anseios da sociedade, proporciona a constituição de direitos de forma mais legítima, pois aquele que gozará do benefício o fará na proporção em ele mesmo sugeriu ao Estado que assim o fizesse.

Dessa forma, a participação do cidadão nos processos decisórios discricionários da administração públi$\mathrm{ca}$, além de contribuir para o dispêndio de recursos de forma mais adequada, representa um fortalecimento da legitimidade do direito conferido pelo Estado ao cidadão.

Não é o Poder Judiciário, mas o próprio destinatário da política social quem tem as melhores condições de contribuir para a aplicação ótima dos recursos. A implementação de uma democracia participativa não só no âmbito da edição de leis orçamentárias, mas no âmbito das decisões discricionárias da administração pública, é elemento fundamental para a aproximação entre o que o Estado proporcio-
Muito embora o tema da participação popular nas decisões administrativas discricionárias seja pouco explorado no Brasil, os estudos e a vivência brasileira acerca do orçamento participativo é um importante objeto de comparação e confere critérios e instrumentos para a criação do ambiente de discussão dentro das decisões executivas relacionadas à efetivação dos direitos sociais.

O tema apresentado neste artigo não tem a pretensão de esgotar todas as possibilidades de comunicação entre a sociedade e o Estado no que tange à formulação e efetivação de políticas públicas relacionadas aos direitos sociais. O foco da análise será o estabelecimento dessa comunicação no âmbito da administração pública e será delimitado por uma análise do direito social à moradia, mais especificamente, dos critérios utilizados pelo Distrito Federal para estabelecer a ordem de classificação dos beneficiários do programa de concessão de moradia.

Essa análise é relevante e representa a questão teórica abordada, pois não há recursos estatais suficientes para se conferir habitação a todos os cidadãos. Com isso, a fixação dos critérios de distribuição de benefícios é tema que revela como o poder público pode se distanciar das demandas efetivas da sociedade quando define esses critérios sem uma discussão ampla perante a sociedade.

Assim, o presente artigo busca contribuir para a legitimidade das decisões administrativas relacionadas à efetivação dos direitos sociais, o que, por consequência, proporciona um gasto mais adequado dos recursos e uma implementação mais adequada das políticas públicas.

\section{A heterogeneidade das demandas e a evo- lução do Estado}

Verificar que as demandas de uma sociedade contemporâneas são plurais é uma tarefa autoevidente. A evolução e as características de uma nação, sejam elas econômicas, históricas ou sociológicas, refletem-se na constituição do povo e nas demandas que este apresenta perante o Estado.

Quando do surgimento do Estado Mderno, a partir da Revolução Francesa, o papel do Estado refletia o anseio liberal da sociedade e a função administrativa precípua era assegurar a liberdade econômica e individual do cidadão, numa separação profunda entre a atividade administrativa e o funcionamento das estruturas sociais.

Mesmo com a transição do Estado Liberal para o Estado Social, a Administração Pública e o próprio di- 
reito administrativo permaneceram com características essencialmente liberais, uma vez que a participação do cidadão nas atividades públicas permaneceu reduzida ${ }^{2}$. Assim, desde o surgimento da administração pública moderna, de mote essencialmente liberal, decorrente dos preceitos da Revolução Francesa, "la separación entre individuo y Estado (o Administración) permanece inalterable, así como la consideración jurídico-administrativa del hombre como individuo"3.

A mesma análise pode ser feita sob uma perspectiva mais ampla, das relações do direito com a democracia e a sociedade, buscando uma resposta satisfatória para a questão da legitimidade do direito.

Ao se inserir nessas questões, Jürgen Habermas ${ }^{4}$ faz um paralelo acerca da legitimação do direito em dois paradigmas distintos, o do Estado Liberal e do Estado Social. No primeiro, a máxima de não intervenção do Estado (até 1900) levou à construção de um modelo jurídico liberal, em que o direito privado era autônomo, fechado, a salvo inclusive da ordem constitucional. Após a Constituição de Weimer, a Constituição passou a permear as relações privadas, de modo que ao legislador era imposto o dever de inserir o conteúdo dos direitos fundamentais às relações privadas. Nesse quadro, surgiram novos direitos, ainda de caráter liberal, mas infiltrados pela justiça social (v. g. direito da concorrência, direito econômico, direito do trabalho etc.).

\footnotetext{
"La continua crisis del Derecho administrativo em nuestro siglo tiene su origen em esa separación entre sus dogmas básicos y la realidad y se agudiza em aquellos períodos históricos em que la eficácia legitimadora de los postulados del Estado de Derecho liberal viene afectada por la puesta em relieve de las contradicciones de la própria realidad a la que se superpone. Por tanto, no es que los dogmas jurídicos del Derecho público del último tercio del siglo pasado reflejasen fotográficamnete la configuración de la sociedad a la que se aplicaban, por lo que pierden vigencia com las transformaciones de la misma, sino que éstas alcanzan en determinados momentos uma proporción tal, em sentido cualitativo, que las divergencias com la teorización jurídica impiden a ésta jugar su doble función de suministradora de soluciones prácticas y aglutinadora de consenso ideológico". SANCHÉZ MORÓN, Miguel. La participacion del ciudadano en la administracion publica. Madrid: Centro de Estudios Constitucionales, 1980. p. 18.

3 SANCHÉZ MORÓN, Miguel. La participacion del ciudadano en la administracion publica. Madrid: Centro de Estudios Constitucionales, 1980. p. 40.

4 HABERMAS, Jürgen. Direito e Democracia: entre faticidade e validade. "Paradigmas do Direito". Tradução: Flávio Beno Siebeneichler, Rio de Janeiro: Tempo Brasileiro, 1997. v. 2. p. 123-190.
}

$\mathrm{Na}$ visão de Habermas, essa mudança do Estado Liberal para o Estado Social representa uma mudança nos paradigmas do direito, uma vez que a autonomia privada do cidadão passa a ser entendida de modo diferente. Enquanto no Estado Liberal a autonomia significava a não interferência absoluta do Estado nas relações privadas, no Estado Social, a liberdade e a autonomia do cidadão só existem se houver condições efetivas de seu exercício e é o Estado quem deve prover essas condições.

Ocorre, contudo, que quanto mais condições procedimentais ou materiais (benefícios) o Estado Social confere ao cidadão, mais este se torna dependente do Estado e, desse modo, mais a autonomia individual é reduzida. Nesse caminho, medidas estatais que seriam destinadas a promover a igualdade material do cidadão acabam por se transformar em verdadeiros projetos paternalistas que promovem a dependência do cidadão ao Estado.

Essa dificuldade que o poder público tem de conferir direitos aos cidadãos na proporção e na medida exata para que, de um lado, o cidadão seja atendido em suas necessidades e, de outro, mantenha sua autonomia privada, não ingressando no processo de dependência relatado, decorre, fundamentalmente, da incapacidade da administração pública assimilar a heterogeneidade dos interesses dos cidadãos ${ }^{5}$.

\section{A amplitude de possibilidade de atendi- mento das demandas sociais e a limitação dos orçamentos públicos}

A complexidade da identificação das demandas sociais e do alcance que o atendimento a elas deve obter ganha um leque ainda maior de possibilidades quando se esta diante da promoção de um direito social.

Isso porque, se por um lado há uma necessidade imperiosa do atendimento aos direitos sociais consagrados na Constituição e nas leis de regência, de outro, há a limitação orçamentária que impossibilita o acesso pleno aos recursos pelos que deles necessitam.

Nesse sentido, o orçamento surge como um aspecto limitador dos direitos sociais e um complicador na tarefa do Estado de distribuir os recursos escassos de uma

SANCHÉZ MORÓN, Miguel. La participacion del ciudadano en la administracion publica. Madrid: Centro de Estudios Constitucionales, 1980. p. 40. 
forma mais justa e na medida necessária para atender de forma isonômica aqueles que necessitam daquele direito social.

Ao destinar os recursos, o gestor público não pode dispensar grande monta em uma localidade ou classe social específica e se esquecer dos demais grupos que necessitam e demandam aquele mesmo direito.

Não há dúvidas de que o equívoco do Estado nesse planejamento distributivo resulta na exclusão de um direito constitucionalmente consagrado ao cidadão. Desse modo, evidencia-se a regra geral descrita por Stephen Holmes e Cass R. Sustein: “As a general rule, unfortunate individuals who do not live under a government capable of taxing and delivering an effective remedy have no legal rights. Statelessness spells rightslessness. A legal right exists, in reality, only when and if it has budgetary costs" .

Se o orçamento público é fator limitador da implementação dos direitos sociais, esse elemento de direito financeiro não pode ser relegado ao segundo plano quando o tema é a efetivação dos direitos fundamentais, sejam eles individuais ou sociais ${ }^{7}$. Pelo contrário, a relação entre a implementação desses direitos e a definição do orçamento é cíclica e autocomplementar: a distribuição dos recursos por meio do orçamento deve ter por mote direto a gama dos direitos individuais consagrados na Constituição, de modo que nenhum desses direitos pode ser esquecido, e a implementação dos direitos só pode ser levada a cabo se houver orçamento disponível para tanto.

A partir dessa relação entre efetivação de direitos sociais e orçamento limitado, a avaliação que se deve fazer é: em que medida e extensão o direito social à saúde/moradia/educação/segurança/lazer/previdência/etc. deve ser implementado?

No campo do direito social à moradia, objeto des-

HOLMES, Stephen; SUNSTEIN, Cass R. The Cost of Rights: Why Liberty Depends on Taxes. New York: W. W. Norton \& Company, Ano. p. 19.

7 "Por isso há uma contradição nesse discurso de que os orçamentos são interesses secundários do Estado, e que os direitos fundamentais devem ser implementados a todo custo. Isto é, como passar pelo discurso de efetivação e aplicação imediata dos Direitos Sociais, sem questionar o uso da despesa pública que é o meio pelo qual o Estado se realiza? É necessária uma mudança de rumo para incluir a discussão orçamentária como principal meio para as finalidades da administração pública." CHRISTOPOULUS, Basile Georges Campos. O orçamento público e a efetivação dos direitos sociais. In: CONGRESSO NACIONAL DO CONPEDI, 18., 2010, Anais..., 2010. p. 8591. te trabalho, esse questionamento abre um amplo leque para as mais diversas indagações. Afinal, os programas habitacionais do Estado devem conferir uma moradia ao cidadão sem qualquer contraprestação deste? Se houver contrapartida, como ela será fixada? Os programas habitacionais devem beneficiar a classe média e classe alta? Qual deve ser o critério de distribuição das moradias doadas pelo Estado? Como organizar os interessados em receber um imóvel em uma ordem justa? O Estado pode destinar moradias ou criar condições especiais àqueles que integram associação de moradores? O Estado pode inserir em programa de moradia aquele que ocupa irregularmente área pública ou que pratica outras infrações à ordem urbanística e ao meio ambiente? Qual o montante arrecadado pelo Estado deve ser destinado à moradia?

Essas perguntas deixam transparecer a grande margem de atuação discricionária do poder público na implementação dos direitos sociais, especialmente em se tratando do direito à moradia.

Não bastassem essas questões, a própria fixação e execução da lei orçamentária revela o caráter discricionário da implementação dos direitos sociais. A execução do que se encontra definido nessa lei pode ser flexibilizado por inúmeros instrumentos a disposição do Poder Executivo, uma vez que não há vinculação legal das despesas ${ }^{8}$.

Christopoulos observa que essa discricionariedade exacerbada:

acaba ofendendo o princípio democrático, que não se esgota com uma maior participação popular na decisão do gasto público, mas numa diminuição da discricionariedade ou opção do administrador público quando da realização do gasto, com uma vinculação maior ao que foi votado nas leis orçamentárias?

Não há dúvidas de que a solução para o problema da discricionariedade exacerbada na escolha do quê fazer com o orçamento público e em que medida atender o direito social $\mathrm{x}, \mathrm{y}$ ou $\mathrm{z}$ só pode estar no princípio democrático em que o destinatário da norma e dos recursos tenha o espaço para auxiliar no preenchimento dessas lacunas.

Esse é o tema que exploraremos a seguir.

$8 \quad$ KRELL, Andreas Joachim. Direitos sociais e controle judicial no Brasil e na Alemanha: os (des)caminhos de um Direito Constitucional "comparado". Porto Alegre: S. Fabris, 2002.

9 CHRISTOPOULUS, Basile Georges Campos. O orçamento público e a efetivação dos direitos sociais. In: CONGRESSO NACIONAL DO CONPEDI, 18., 2010, Anais..., 2010. p. 8593. 


\section{A participação do indivíduo no "como" aten- der às demandas sociais}

A Constituição Federal prevê que nenhuma lesão ou ameaça a direito pode ser excluída da apreciação do Poder Judiciário (art. 5 XXXV). Diante dessa previsão, que consagra o princípio da inafastabilidade da jurisdição, e de que os direitos sociais são direitos assegurados aos cidadãos, criou-se a cultura, no Brasil, de que todos os problemas, inclusive os de planejamento e de estruturação das políticas públicas ${ }^{10}$, devem ser resolvidos pelo Poder Judiciário.

Se é verdade que o Poder Judiciário deve atuar nos casos em que os órgãos estatais competentes descumprem os encargos político-jurídicos que sobre eles incidem de implementar os direitos sociais ${ }^{11}$, não é menos verdade que o Poder Judiciário não é a estrutura competente e nem tem meios procedimentais para solucionar a questão de uma forma global, ou seja, de forma a direcionar os escassos recursos do orçamento de uma forma geral, uniforme, justa e que atenda a todos os direitos consagrados na Constituição, na medida do possível.

Por essa razão, Maria Paula Dallari Bucci ${ }^{12}$ expõe:

$\mathrm{O}$ efeito indesejado que pode decorrer desse fato é o deslocamento (e desorganização) do processo de seleção de prioridades e reserva de meios, cerne da construção de qualquer política pública, dos Poderes Executivo e Legislativo, onde se elabora o planejamento e se define, como consequência, o orçamento público, segundo uma ótica global, para o contexto isolado de cada demanda judicial, cuja perspectiva, mesmo nas ações coletivas, é do indivíduo ou grupo de indivíduos (ou talvez de uma comunidade, mas nunca ou quase nunca com a mesma abrangência das leis orçamentárias, de âmbito municipal, estadual ou federal).

No caso do direito à moradia, a dificuldade de atuação do Poder Judiciário é ainda maior, uma vez que a constatação do descumprimento desse direito social por

10 Entendida neste trabalho como programa de ação governamental, visando realizar objetivos determinados BUCCI, Maria Paula Dallari. O conceito de política pública em Direito. In: BUCCI, Maria Paula Dallari (Org.). Políticas públicas: reflexões sobre o conceito jurídico. São Paulo: Saraiva, 2006. p. 11.

11 BRASIL, Supremo Tribunal Federal. Decisão do Ministro Celso de Mello no AgRg no RE 410.715.

12 BUCCI, Maria Paula Dallari. O conceito de política pública em Direito. In: BUCCI, Maria Paula Dallari (Org.). Políticas públicas: reflexões sobre o conceito jurídico. São Paulo: Saraiva, 2006. p. 36. parte do Estado, na maioria dos casos, não demanda um remédio urgente e imediato. Ao contrário do que ocorre com as demandas judiciais com fundamento no direito à saúde - em que o indivíduo requer um medicamento, uma internação em UTI ou uma cirurgia necessária para a continuidade de sua vida - uma demanda que requeira a doação de uma casa popular ou a implementação de uma política habitacional imediatamente, dificilmente receberá uma resposta efetiva e urgente do Poder Judiciário.

Nesse quadro, somente uma discussão democrática, com a efetiva participação da sociedade, do Estado e dos beneficiários dos direitos sociais é capaz de definir "como" (em que amplitude e em quais condições) o direito social à moradia deve ser atingido, diante da escassez dos recursos orçamentários.

Nesse sentido, a teoria habermasiana oferece um importante norte, pois, a partir da análise da dicotomia entre os paradigmas do direito do Estado Liberal e do Estado Social, Habermas considera que a autonomia do indivíduo só será efetivamente consagrada e o direito só será efetivamente implementado se este surgir a partir da formação discursiva da opinião e da vontade do cidadão, ou seja, se o próprio destinatário do direito (que é também o que alimenta os recursos do orçamento) ingressar efetivamente no diálogo que busca um consenso acerca do problema proposto:

Entretanto, a disputa entre os dois paradigmas, que ainda perdura, limita-se à determinação dos pressupostos fáticos para o status de pessoas do direito em seu papel de destinatárias da ordem jurídica. Todavia, elas somente serão autônomas na medida em que puderem se entender também como autoras do direito ao qual se submetem enquanto destinatárias.

Ao tratarmos da fundamentação do sistema dos direitos, descobrimos que a autonomia das pessoas privadas remete à legitimidade do direito e vice-versa. Sob as condições de uma compreensão pós-metafísica do mundo, só tem legitimidade o direito que surge da formação discursiva da opinião e da vontade de cidadãos que possuem os mesmos direitos. Estes, por seu turno, só podem perceber, de maneira adequada, sua autonomia pública, garantida através de direitos de participação democráticos na medida em que sua autonomia privada for assegurada. ${ }^{13}$

13 HABERMAS, Jürgen. Direito e Democracia: entre faticidade e validade. "Paradigmas do Direito". Tradução: Flávio Beno Siebeneichler, Rio de Janeiro: Tempo Brasileiro, 1997. v. 2. p. 146. 
O modelo de participação cidadã, na classificação proposta por Sintomer, Herzberg e Röcke, que mais se aproxima da ideia de Habermas de que o direito legítimo surge da "formação discursiva da opinião e da vontade de cidadãos que possuem os mesmos direitos" é o de democracia participativa, assim definido:

Sua principal característica é o surgimento simultâneo de um 'quarto poder' (participantes têm um efetivo poder decisório, distinto daqueles do judiciário, do legislativo e do executivo) e de um 'poder compensatório' (a mobilização autônoma da sociedade civil dentro do processo leva ao empoderamento das pessoas e à promoção de formas cooperativas de resolução de conflitos). Nesse modelo, a participação tem repercussões reais em termos de justiça social e de relações entre a sociedade civil e o sistema político.

[...] ele implica que os mecanismos tradicionais de governo representativo estão vinculados a procedimentos democráticos diretos, nos quais habitantes não eleitos (e seus delegados investidos de um 'mandato semi-imperativo') têm de fato poder de decisão, embora, legalmente, a decisão política permaneça nas mãos dos representantes eleitos. ${ }^{14}$

O efetivo exercício de um "quarto poder", que, na verdade, nada mais é do que a materialização do único poder reconhecido constitucionalmente - o povo deve estar presente não só no âmbito do Poder Legislativo, quando da votação do orçamento ou da lei que cria e confere balizas a uma determinada política pública, mas no âmbito do Poder Executivo, quando da análise do projeto de lei orçamentária e, também, quando da adoção de atos administrativos discricionários que estejam diretamente relacionados com a efetivação de políticas públicas, como, por exemplo, em uma regulamentação que busca conferir critérios de classificação para os beneficiários de moradia em programa habitacional.

No âmbito do direito administrativo, a participação dos administrados nos processos de decisão discricionária dos gestores públicos é um elemento capaz de diminuir as disfunções organizativas e burocráticas e, principalmente, proporcionar um novo espaço de consenso entre a ação estatal e a vontade geral. Nesse sentido, o espaço de discussão entre interessados, destinatários dos direitos e gestores públicos confere uma maior legiti-

14 SINTOMER, Yves; HERZBERG, Carsten; RÖCKE, Anja. Modelos transnacionais de participação cidadã. Revista Sociologias, Porto Alegre, ano 14, n. 30, p. 100-101, maio/ago. 2012. midade às decisões administrativas, o que acaba por superar o vácuo da relação entre aquilo que o Estado provê e os serviços que o cidadão realmente necessita obter dos limitados recursos orçamentários ${ }^{15}$.

Se é certo que a administração pública brasileira evoluiu, a partir da década de noventa, de um modelo burocratizado para o modelo gerencial ${ }^{16}$, com ênfase no controle dos resultados e orientação da ação do Estado para o cidadão-usuário, a segunda década do século XXI dá demonstrações de que o Estado se apresenta de forma mais aberto e transparente ao cidadão e de que o cidadão demanda por participação nas decisões estatais.

A edição de normas que conferem transparência às ações estatais (Lei ${ }^{\circ} 12.527 / 2011$, Decreto $n^{\circ}$ $7.724 / 2012$ e leis estaduais que difundem o acesso à informação) e as manifestações populares iniciadas em junho de 2013 abrem caminho para a atuação mais efetiva dos destinatários das decisões administrativas no processo de escolha que antes era pautado, tão somente, pelo poder discricionário do administrador.

Assim como a adoção do orçamento participativo, inicialmente em Porto Alegre e, em seguida, em todos os continentes do mundo ${ }^{17}$, inseriu a comunidade nas discussões acerca da alocação dos recursos públicos, instrumentos análogos devem ser adotados no âmbito da Administração para aproximar as escolhas dos gestores das pretensões dos cidadãos.

Quando o objeto do gasto público é a implementação de um direito social, não basta proporcionar a participação de cidadãos não eleitos na elaboração do orçamento público - como ocorre no orçamento participativo -, esses mesmos cidadãos devem participar também na elaboração dos critérios de distribuição dos benefícios provenientes desses recursos.

Nesse sentido, se, por exemplo, o Estado busca implementar o direito social à moradia, não basta a participação do cidadão na definição da quantidade de recursos que deve ser destinado em cada uma das ações

15 ENTERRÍA, García de; FERNÁNDEZ, Tomás-Ramón, Curso de Derecho Administrativo. 12. ed. New York: Thomson Reuters, 2011. p. 87.

16 PEREIRA, Luiz Carlos Bresser. 1934: a reforma do Estado dos anos 90: lógica e mecanismos de controle. Brasília: Ministério da Administração Federal e Reforma do Estado, 1997.

17 SINTOMER, Yves; HERZBERG, Carsten; RÖCKE, Anja. Modelos transnacionais de participação cidadã. Revista Sociologias, Porto Alegre, ano 14, n. 30, p. 77, maio/ago. 2012. 
nessa política. A implementação desse direito será mais legítima e eficiente se o cidadão participar, efetivamente, do estabelecimento dos critérios adotados na doação de imóveis para moradia ou na definição de quais grupos será destinatário dos financiamentos subsidiados para a construção de imóveis, por exemplo.

Com isso, o fim do "autoritarismo discricionário" dos gestores públicos poderia ocorrer, assim como ocorreu na gênese do orçamento participativo ${ }^{18}$, a partir da abertura promovida pela própria administração pública para assembléias populares locais (de bairros ou de pequenos municípios), com reuniões frequentes e ampla participação, com a eleição periódica de delegados responsáveis por levar as decisões de sua base territorial a conselhos participativos mais amplos em distritos e municípios maiores, bem como a instituição de mecanismos transparentes de demonstração de resultados e de controle popular.

Esse modelo diminuiria o clientelismo e o fim eleitoreiro que está por traz dos decretos e regulamentações relativos a benefícios sociais editados a partir de estudos ocultos ou de discussões em comitês formados por apadrinhados políticos ou por membros dos partidos do governo.

A hipótese proposta neste trabalho ficará mais clara no desenvolvimento do tópico seguinte, no qual será analisado o decreto que regulamenta os critérios utilizados pelo governo para o estabelecimento de uma ordem de beneficiários do programa habitacional do Distrito Federal.

\section{0 critério de classificação dos beneficiários dos programas de moradia no Distrito Fe- deral}

Não há dúvidas de que é dever constitucional do Estado (art. $6^{\circ}$ e 23, IX, da Constituição) promover a moradia. Contudo, as definições e os procedimentos de efetivação desse direito social formulado no âmbito do Distrito Federal acabam por representar uma das diversas demonstrações daquilo que Habermas definiu como o esvaziamento da autonomia privada do cidadão promovida pelo Estado Social, diante da reduzida legitimidade do direito conferido àquele que não participou do processo de criação das condições da efetivação desse direito.

18 SINTOMER, Yves; HERZBERG, Carsten; RÖCKE, Anja. Modelos transnacionais de participação cidadã. Revista Sociologias, Porto Alegre, ano 14, n. 30, p. 78, maio/ago. 2012.
A Lei distrital no $3.877 / 06$, que dispõe sobre a política habitacional no âmbito do Distrito Federal, se propõe a solucionar a "carência habitacional para todos os segmentos sociais, com prioridade para a população de média e baixa renda" (art. $2^{\circ}$ ). Além disso, a norma orienta a ação do Governo do Distrito Federal na política habitacional, determinando a realização de ações para a promoção do direito à moradia, dentre essas ações, encontram-se: (a) oferta de lotes com infra-estrutura básica; (b) atendimento prioritário às comunidades localizadas em áreas de maior concentração de baixa renda, garantido o financiamento para habitação; (c) aumento da oferta de áreas destinadas à construção habitacional; (d) atendimento do banco de dados dos inscritos nos programas habitacionais; (e) prioridade às cooperativas habitacionais de trabalhadores na aquisição de áreas públicas urbanas destinadas a habitação.

Nesse sentido, a partir da distinção conceitual promovida por Fernando Aith entre política de Estado e política de governo quanto aos objetivos, a Lei distrital $\mathrm{n}^{\circ}$ $3.877 / 06$ caracteriza-se como uma política de governo ${ }^{19}$.

Dentre os dispositivos da Lei distrital $\mathrm{n}^{\circ} 3.877 / 06$, o artigo $4^{\circ}$ e sua regulamentação são os exemplos mais claros de que a abertura do processo decisório da administração pública é fundamental para se conferir ao cidadão o direito à moradia na extensão necessária para não gerar a dependência do indivíduo ao Estado, identificada por Habermas, bem como para reduzir o âmbito das decisões autoritárias e distantes da realidade promovidas pela administração pública burocratizada, mencionada por García de Enterría.

$\mathrm{O}$ artigo $4^{\circ}$ da Lei distrital no $3.877 / 06$ prevê que só pode participar de programa habitacional de interesse social no âmbito do Distrito Federal aquele que atender, cumulativamente, aos seguintes requisitos: (I) ter maioridade ou ser emancipado; (II) residir no Distrito Federal nos últimos cinco anos; (III) não ser, nem ter sido proprietário, promitente comprador, cessionário ou usufrutuário de imóvel residencial no Distrito Federal; (IV) ter renda familiar de até doze salários mínimos.

"Quando, de outro lado, os objetivos das políticas públicas forem o de promover ações pontuais de proteção e promoção aos direitos humanos específicos expressos em nossa Carta, pode-se falar em política de governo" AITH, Fernando. Políticas públicas de Estado e de governo: instrumentos de consolidação do Estado democrático de direito e de promoção e proteção dos direitos humanos. In: BUCCI, Maria Paula Dallari (Org.). Políticas públicas: reflexões sobre o conceito jurídico. São Paulo: Saraiva, 2006. p. 235. 
Ao regulamentar esse dispositivo, o Decreto distrital $n^{\circ} 33.964 / 2012$ implementou um sistema de pontuação para que os interessados fossem cadastrados em uma ordem de classificação de acordo com os requisitos estabelecidos na Lei no 3.877/06. Assim, aquele que obtém pontuação maior, se posiciona numa posição mais avançada da fila e fica mais perto de ser beneficiado com uma residência, por exemplo.

A pontuação varia de acordo com o tempo que a pessoa reside no Distrito Federal, tempo de inscrição em programa habitacional, número de dependentes na família, e famílias com pessoa com deficiência ou idosa ${ }^{20}$.

Contudo, diante da falta de participação comunitária na fixação dos critérios, seria plausível crer que os fatores preponderantes para colocar determinado indivíduo numa colocação melhor que outro poderiam ser diversos daqueles estabelecidos discricionariamente pela administração pública.

Diante da constatação de que o brasileiro não é dado a formalismos, é bem provável que a comunidade beneficiária do direito à moradia não daria tanta relevância ao tempo

20 1. PARÂMETROS

1.1 Tempo de residência no Distrito Federal: 4.000 pontos, distribuídos diretamente proporcional ao tempo apurado com base nos dados cadastrais;

1.2 Tempo de inscrição em Programas Habitacionais no DF: 1.500 pontos, distribuídos diretamente proporcional ao tempo apurado com base nos dados cadastrais;

1.3 Número de dependentes na família: 2.500 pontos, assim distribuídos.

\begin{tabular}{|c|c|}
\hline 01 dependente & 500 \\
\hline 02 dependente & 1.000 \\
\hline 03 dependente & 1.500 \\
\hline 04 dependente & 2.000 \\
\hline 05 ou mais dependentes & 2.500 \\
\hline
\end{tabular}

1.4 Famílias com condições especiais - pessoas com deficiência ou pessoas com mais de 60 (sessenta) anos: 1.500 pontos, assim distribuídos.

\begin{tabular}{|l|c|c|}
\hline & A & B \\
\hline $\begin{array}{l}\text { Família com 01 membro com condi- } \\
\text { ções especiais }\end{array}$ & 300 & 600 \\
\hline $\begin{array}{l}\text { Família com 02 membros com condi- } \\
\text { ções especiais }\end{array}$ & 600 & 900 \\
\hline $\begin{array}{l}\text { Família com 03 membros com condi- } \\
\text { ções especiais }\end{array}$ & 900 & 1.200 \\
\hline $\begin{array}{l}\text { Família com 04 ou mais membros } \\
\text { com condições especiais }\end{array}$ & 1.200 & 1.500 \\
\hline
\end{tabular}

(A) Grupo familiar em que o candidato não tem condições especiais.

(B) Grupo familiar em que o candidato tem condições especiais.

1.5. Renda familiar mensal bruta per capita: 500 pontos, distribuídos inversamente proporcionais ao valor da renda mensal bruta per capita apurada com base nos dados cadastrais; de inscrição em programas habitacionais como o fez o decreto em foco. Certamente, a solidariedade ínsita ao brasileiro faria preponderar questões sociais e dificuldades vividas pelos interessados (v. g. doentes em situação grave na família, perda do chefe de família, etc.) sobre aspectos formais como o tempo de residência no Distrito Federal. Outros poderiam pleitear que os tributos arrecadados por um cidadão ao longo da vida poderia ser critério para situá-lo numa posição mais privilegiada da fila. A comunidade poderia, também, inserir critérios que significassem um estímulo ao desenvolvimento da própria comunidade, como o trabalho voluntário em creches, na limpeza de ruas, na promoção de eventos etc. Por outro lado, aquele que promovesse ações que prejudicassem a comunidade poderia sofrer redução em sua pontuação e assim por diante.

Esse leque de possibilidades se insere apenas na regulamentação de um dispositivo legal. Milhares de outras decisões com a participação efetiva da sociedade poderiam ser tomadas se toda a política governamental de promoção à moradia fosse aberta à discussão.

Os questionamentos e sugestões quanto à ordem de classificação dos beneficiários do programa habitacional do Distrito Federal servem muito mais para demonstrar que um sem número de outros critérios poderia ser eleito pelos destinatários dos benefícios como ideais para promover a ordem de classificação dos interessados do que para esgotar as possibilidades de evolução do decreto.

Ademais, não se busca aqui identificar um modelo de classificação ideal, mas demonstrar que, qualquer que seja o resultado final decorrente da deliberação coletiva em um ambiente em que se busca o consenso, a solução adotada aproximará a política de governo das demandas efetivas da sociedade, evitará as disparidades geradas pelo modelo de decisão estatal burocrática e promoverá uma maior legitimidade ao direito promovido.

Metaforicamente, a regulamentação realizada pelo Poder Executivo sem a participação do cidadão é o mesmo que a prescrição de um medicamento poderoso sem a presença do paciente no consultório. O paciente corre sério risco de se tratar com um remédio inadequado - ou por ser insuficiente ou por conter mais substâncias químicas do que o necessário - , mais dispendioso do que outros disponíveis no mercado e, ao final do tratamento, a doença seria inadequadamente tratada, fazendo a doença criar resistência ao medicamento insuficiente ou fazendo o corpo convalescer e passar a depender do remédio poderoso, e o orçamento do cidadão seria afeta- 
do negativamente pela compra de um bem que atendeu as suas necessidades.

Assim como o médico deve ter a presença do paciente em seu consultório para prescrever tratamentos, o Estado deve trazer as vozes da sociedade para o ambiente de decisão administrativa ao delinear as políticas sociais. A evolução administrativa promovida com o orçamento participativo deve ser experimentada em momentos cruciais de tomada de decisão no âmbito do Poder Executivo, especialmente naquelas decisões que serão estabelecidos critérios de como atender de forma mais eficiente, uniforme e justo determinado direito social.

\section{Conclusões}

Diante da necessidade de aproximação das decisões administrativas discricionárias relativas à implementação dos direitos sociais às demandas efetivas da sociedade, percebe-se que não há outro caminho senão a criação de espaços de discussão e consenso os quais proporcionarão uma ampla discussão entre a sociedade e a administração pública.

A observação acima realizada, da regulamentação de um ponto específico de uma lei local que dá contornos à política de promoção do direito à moradia, revela que a ampla margem de discricionariedade na concessão de direitos sociais pode, facilmente, gerar distorções em todo o sistema de promoção desses direitos.

O modelo estabelecido no orçamento participativo é uma importante fonte de comparação que propicia uma adaptação do procedimento ali estabelecido para o estabelecimento de um diálogo permanente entre sociedade e administração pública.

Nesse ambiente, as decisões administrativas ensejarão gastos públicos mais adequados e fortalecerão a legitimidade do direito conferido pelo Estado ao cidadão.

Em se tratando de implementação de política pública relacionada a direitos sociais, não é o Poder Judiciário quem dará a solução final e ótima para o Estado, mas sim o diálogo entre próprio destinatário da política social e a administração pública, pois o primeiro sabe das reais necessidades e o segundo tem a quantificação dos recursos disponíveis.

\section{Referências}

AITH, Fernando. Políticas públicas de Estado e de governo: instrumentos de consolidação do Estado democrático de direito e de promoção e proteção dos direitos humanos. In: BUCCI, Maria Paula Dallari (Org.). Políticas públicas: reflexões sobre o conceito jurídico. São Paulo: Saraiva, 2006.

BRASIL, Supremo Tribunal Federal. Decisão do Ministro Celso de Mello no AgRg no RE 410.715.

BUCCI, Maria Paula Dallari. O conceito de política pública em Direito. In: BUCCI, Maria Paula Dallari (Org.). Políticas públicas: reflexões sobre o conceito jurídico. São Paulo: Saraiva, 2006.

CHRISTOPOULUS, Basile Georges Campos. O orçamento público e a efetivação dos direitos sociais. In: CONGRESSO NACIONAL DO CONPEDI, 18., 2010, Anais..., 2010. p. 8591.

ENTERRÍA, García de; FERNÁNDEZ, Tomás-Ramón, Curso de Derecho Administrativo. 12. ed. New York: Thomson Reuters, 2011.

HABERMAS, Jürgen. Direito e Democracia: entre faticidade e validade. "Paradigmas do Direito". Tradução: Flávio Beno Siebeneichler, Rio de Janeiro: Tempo Brasileiro, 1997.

HOLMES, Stephen; SUNSTEIN, Cass R. The Cost of Rights: Why Liberty Depends on Taxes. New York: W. W. Norton \& Company.

KRELL, Andreas Joachim. Direitos sociais e controle judicial no Brasil e na Alemanha: os (des)caminhos de um Direito Constitucional "comparado". Porto Alegre: S. Fabris, 2002.

SANCHÉZ MORÓN, Miguel. La participacion del ciudadano en la administracion publica. Madrid: Centro de Estudios Constitucionales, 1980.

PEREIRA, Luiz Carlos Bresser. 1934: a reforma do Estado dos anos 90: lógica e mecanismos de controle. Brasília: Ministério da Administração Federal e Reforma do Estado, 1997.

QUEIROZ, Cristina. Direitos fundamentais: teoria geral. 2. ed. Coimbra: Coimbra Editora, 2010.

SINTOMER, Yves; HERZBERG, Carsten; RÖCKE, Anja. Modelos transnacionais de participação cidadã. Revista Sociologias, Porto Alegre, ano 14, n. 30, p. 77, maio/ago. 2012. 